\title{
Finite element modelling to predict machining induced residual stresses in the end milling of hard to machine Ti6Al4V alloy
}

\author{
K Prakash Marimuthu ${ }^{1}$, H P Thirtha Prasada ${ }^{2}$, and C S Chethan Kumar ${ }^{3}$ \\ ${ }^{1}$ Department of Mechanical Engineering, Amrita School of Engineering, Bengaluru, Amrita Vishwa Vidyapeetham, India. \\ ${ }^{2}$ Department of Computer Aided Engineering, Visvesvaraya Institute of Advanced Technologies, Visvesvaraya Technological \\ University, India \\ ${ }^{3}$ Department of Industrial Engineering \& Management, M S Ramaiah Institute of Technology, India
}

\section{Article Info}

Article history:

Received Sept 29, 2018

\section{Keyword:}

Machining

Residual stresses

Johnson-Cook mode

oblique cutting

simulation

\begin{abstract}
Machining is one of the methods to produce components and products from raw material. Many factors influence the outcome of the machining process and the life of the components there after. Researchers have tried to understand the underlying principles of machining using finite element analysis since many years. In the present work the authors have made an attempt to study few behaviour namely, stress distribution, force variation and machining induced residual stresses while machining hard to machine Ti6Al4V alloy using finite element analysis. The model that is presented in this work is an improvisation of some of the existing models overcoming some of the shortcomings of the existing model. The work presented here uses the time tested Johnson-Cook model, but unlike the many other works sacrificial layers is not being used rather, Johnson-Cook damage model is being used. In addition, the authors have considered opted for oblique cutting in spite of high computational time due to the want of more accurate results.
\end{abstract}

\section{Corresponding Author:}

First Author,

Departement of Mechanical Engineering,

Amrita School of Engineering, Bengaluru,

Amrita Vishwa Vidyapeetham, India.

Email: k_prakash@blr.amrita.edu

\section{Introduction}

Machining is one of the important processes to produce net shape components. During the machining process, the component undergoes changes. It undergoes physical as well as metallurgical changes. One of the crucial parameters of importance is the residual stresses induced during machining. Residual stresses are integral part of structures and components. Any component produced by plastically deforming by various manufacturing processes will have the residual stresses. The nature and magnitude has favourable as well as detrimental consequence to the components functional performances. Machining produces two types of residual stresses namely tensile and compressive residual stresses. Machining induced residual stresses have drawn interest of many researchers. Researches have done extensive review on residual stresses but there in no one strong consensus. Key challenge while dealing with residual stresses is the prediction and determination. Many residual stresses measurement technique are available. Researchers sort to experimental, numerical as well as analytical methods to determine the residual stresses. Majority of the researchers using the above method assume that the cutting process is orthogonal cutting process. In actuality, in majority of the cases, oblique cutting is happening. Residual stresses study has become the cynosure of the research community owing to the fact that on the nature and magnitude of their presence, affects the functionality of the structures/components. 
It can affect the fatigue life of the components. Studies are there on how the residual stresses effect the distortion in thin wall machining, it can affect the corrosion resistance of the material.

Titanium, Ti6Al4V is known to be a difficult to machine material [1]. Many researchers have studied various aspects of machining of titanium alloy, from chip formation [2], temperature variation, force variation to residual stresses induced during machining process [3]-[5]. Majority of the researchers have used numerical methods to predict the different parameters of the cutting process. It has been observed from the literature, that the numerical methods have helped the research fraternity to unearth the underlying principles of machining [6]-[11].

As such the machining process is a very complex phenomenon, therefore many of the research has been restricted to orthogonal machining (Ramesh et al., 2015; Ducobu, Rivière-Lorphèvre and Filippi, 2015; Ducobu et al., 2017). The three main machining parameters are the speed, feed and depth of cut. When it comes to the orthogonal machining, it is difficult to incorporate all the machining factors [12] in the simulation model and we are forced to have some assumptions, which prevents us from getting exact results. In practicality, the machining process is oblique metal cutting in majority of the cases and very rarely research on oblique cutting is taking place. In the present work the authors have attempted to model a $3 \mathrm{~d}$ oblique cutting model to predict the residual stresses that are induced during the machining of the titanium alloy. In this work end-milling of titanium alloy is considered for simulation purposes.

End-milling process with a 4-flute tool is considered and one slot is being cut and the residual stresses that are induced is obtained from the simulation. Apart from the residual stresses variation, von-Mises stress distribution and the force variation during the cutting process is also obtained. The setting up of the process, the simulation and the results obtained are explained in the following sections. Key features of the work include : 1) Oblique cutting is being modelled, 2) Johnson-Cook material and damage model is being used, 3) No sacrificial layer is used for damage of material, 4) Model results are compared with the experimental results of AISI 1045 steel.

\subsection{Research Gap}

Many of the reseaches that have been carried out pertaining to orthogonal cutting and mostly researchers have restrained themselves to $2 \mathrm{D}$ analysis owing to high computational time. Also the authors of the present work have observed that use of sacrificial layers for the element deletion effects the chip formation and hence the results would be influenced. Reseaches mainly analyse the chip formation process, so the analysis are being done for a very, very short time interval. The present work tries to address these research gaps. It deals with the 3D analysis of Titanium machining, oblique cutting is presented which is close to reality and sacrificial layer has not been used. In the present work one full pass of material removal is being considered unlike many other researches which deals with only the chip formation. Apart from addressing these research gaps, the authors have focused of the determination of the residual stresses, which is a tedious task. It is quite expensive process. Although less expensive processes are available, it is not accurate. Finite element analysis is not only less expensive, it is also relatively accurate when the above issues are addressed. The drawback being the computiaonal time which is not denied. The input to the analysis is provided so that further research can be undertaken to conquer newer frontiers in the area of machining simulation.

\section{Finite Element Analysis}

\subsection{Modelling}

A dynamic explicit analysis was done in this work using a commercially available software, Abaqus. In the present work a mechanical model is designed, meaning the tool is considered to be rigid and the work piece is considered to be deformable. By doing so, the focus is the mechanical behaviour of the process than the temperature aspects. This in one way reduces the overall computation time also. The tool that was used for the analysis was a 4-flute end-mill cutter. Owing to the complexity in the design of the tool, a cad model of the tool was imported into the work environment. The work piece was designed within the software itself. The assembled view of the work piece and the tool is shown in Fig. 1. 


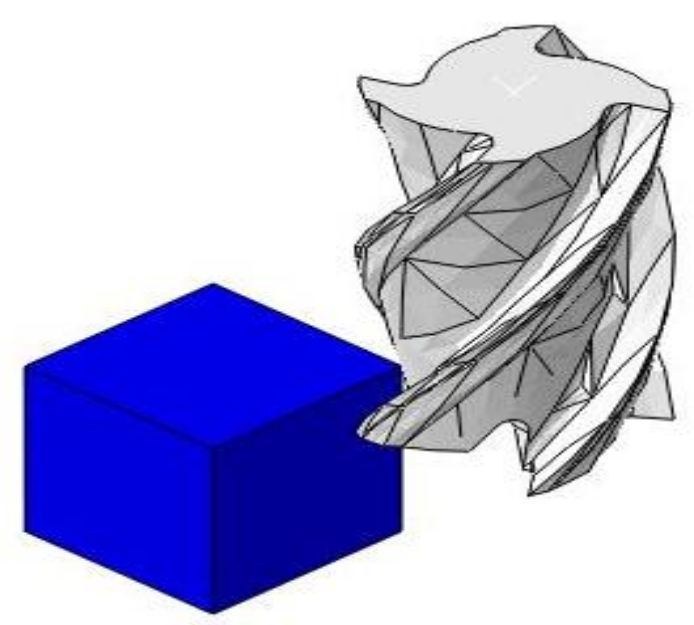

Fig. 1 Assembled view of the work piece and the tool.

\subsection{Material modelling}

The key aspect of numerical simulation of the machining process is the material modelling. For that matter, it is the core of any simulation work. The machining process being complex, many methods are there to do the material modelling. In the machining process large strains occur, there is work hardening, there is temperature variation due to the contact between the work piece and the tool. A model which could capture the different aspects of the machining process is necessitated to properly simulate the machining process. In the present work Johnson-Cook material model is being considered. The material model constants are obtained from Split-Hopkinson test. Another important aspect of the material modelling is the defining the criteria at which the material will fail, otherwise called as the damage criteria. I has been observed that the Johnson-Cook damage model along with the material model works more effectively than the other models that are available namely the shear model, Zerilli-Armstrong flow stress, Steinberg-Cochran-Guinan-Lund flow stress model etc. The material constants that were used in the numerical analysis is shown in Table 1 and Table 2. The material properties are shown in Table 3.

Table 1 Johnson-Cook material Model for Ti6Al4V [15].

\begin{tabular}{lccrrr}
\hline & $\mathbf{A}(\mathbf{M P a})$ & $\mathbf{B}(\mathbf{M P a})$ & $\mathbf{C}$ & $\mathbf{n}$ & $\mathbf{m}$ \\
\hline Ti6Al4V & 862 & 331 & 0.012 & 0.34 & 0.8 \\
\hline
\end{tabular}

Table 2 Johnson-Cook material model for Ti6Al4V [16].

\begin{tabular}{cccccccc}
\hline & $\mathrm{D}_{1}$ & $\mathrm{D}_{2}$ & $\mathrm{D}_{3}$ & $\mathrm{D}_{4}$ & $\mathrm{D}_{5}$ & $\mathrm{~T}_{\text {melt }}$ & $\mathrm{T}_{\text {room }}$ \\
\hline Ti6A14V & -0.09 & 0.25 & -0.5 & 0.014 & 3.87 & $1670^{\circ} \mathrm{C}$ & $25^{\circ} \mathrm{C}$ \\
\hline
\end{tabular}

\subsection{Loading and Boundary condition}

The model with the boundary conditions and different loads that are used is shown in Fig. 2. 


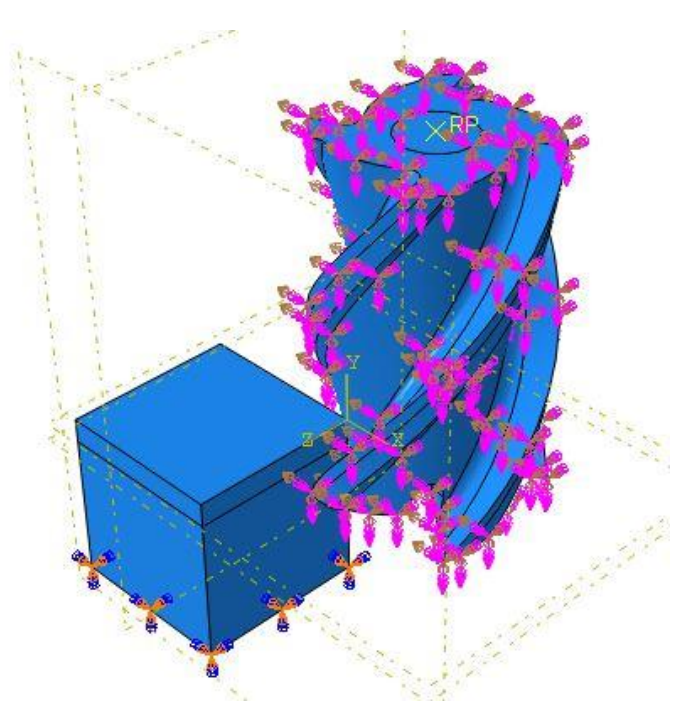

Fig. 2 Model with Boundary condition and Loads.

The bottom of the work piece is arrested for all degree of freedom at the bottom. The tool on the other hand is restricted for translation motion in the $\mathrm{Z}$ - axis and $\mathrm{Y}$ - axis. It is free to move in the $\mathrm{X}$ - axis. The feed is given in the $\mathrm{X}$ direction, the cutting speed, as Rpm is given about the $\mathrm{Y}$ - axis. The depth of cut is given in the Zaxis. The different cutting conditions that were used for the numerical simulation purpose is shown in Table 3 .

Table 3 Cutting conditions used in the simulation.

\begin{tabular}{cc}
\hline & Cutting speed: $700,900,1200 \mathrm{rpm}$ \\
Cutting condition 1 & Feed: $120 \mathrm{~mm} / \mathrm{min}$ \\
& Depth of Cut: $0.3 \mathrm{~mm}$ \\
\hline & Cutting speed: \\
Cutting condition 2 & Feed: $80,100,120,150,180 \mathrm{~mm} / \mathrm{min}$ \\
& Depth of Cut: 0.3 \\
\hline
\end{tabular}

\subsection{Contact and Meshing}

In the present work a simple Coulomb friction is considered between tool and the work piece. The coefficient of friction of 0.2 was used between the tool and work piece. A surface-to-surface contact is established making the tool as the master surface, which can effect deformation in the material on which it comes into to contact and the work piece, is considered to be slave surface. The tool is considered as rigid as mentioned earlier. The work piece was meshed with C3D8R elements [17] and the tool was meshed with C3D10M elements. The size of the element is $0.01 \mathrm{~mm}$. Mapped mess was used to reduce the impact of the size of mesh on the analysis. There is no sacrificial layers used as stated in the research gap. Reduced integration elements are being used in order to reduce the computation time. The meshed model is shown in Fig. 3. Unlike majority of the researches that is available a sacrificial layer is not used. The volume of the work piece is of most interest is provided with a fine mesh and the other region is made of coarse meshed so that the number of elements is minimized.

\subsection{Simulation}

Simulations were run for different step times, The results of simulation at the end of different time steps are given in Fig 4. It was found that $2.5 \mathrm{~s}$ of time step is required to complete one complete pass of the tool over the work piece. The experiment were done and the residual stresses were measured after one complete pass. To mimic the experiments an explicit dynamic analysis was done for a duration of $2.5 \mathrm{~s}$. that is the time taken for the tool to complete one full pass and not just initiation of the chip formation. Figure 4. (a), (b) and (c) 
shows that the end of simulation at different step times and Fig. 4 (d) shows the actual experimental specimen. For the completion of one pass similar to that of the experiment, $2.5 \mathrm{~s}$ is required. Element deletion was adopted in the model so as to obtain the chip formation. Force variation and residual stresses variation was studied whose results are discussed in the following sections.

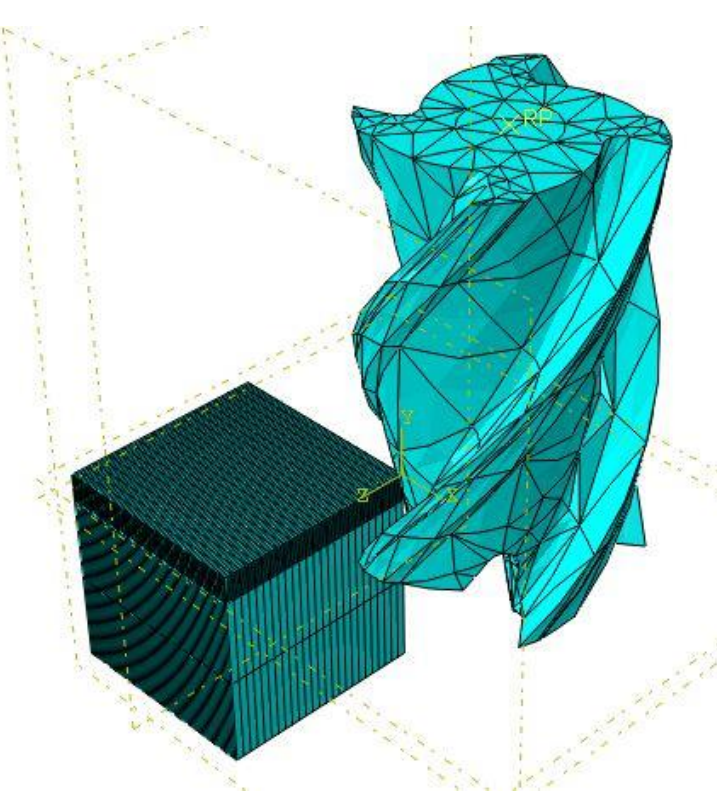

Fig. 3 Meshed model.

\begin{tabular}{|l|l|l|}
\hline Step: Step: Frame: 150 \\
Total Time: 1.500000
\end{tabular}

Fig. 4 Simulation at the end of diffent time steps (a) Step time $=1.5 \mathrm{~s}$ (b) Step time $=2 \mathrm{~s}$ (c) Step time $=2.5 \mathrm{~s}$ (d) Experimental Specimen

\section{Results and Discussion}

After the simulation completed, the chip formation was observed. The von-Mises stress distribution, force variation and the residual stresses variation was studied for different cutting conditions. Keeping the feed rate 
at $120 \mathrm{~mm} /$ minute and depth of cut at 0.3 as constant the force variation at 700, 900, and $1200 \mathrm{rpm}$ was studied. The force variation is given in Fig. 5. The force variation with respect to varying feed rate keeping other factors as constant is given in Fig. 6. The milled specimen with the von-Mises stress distribution is given in Fig. 7.

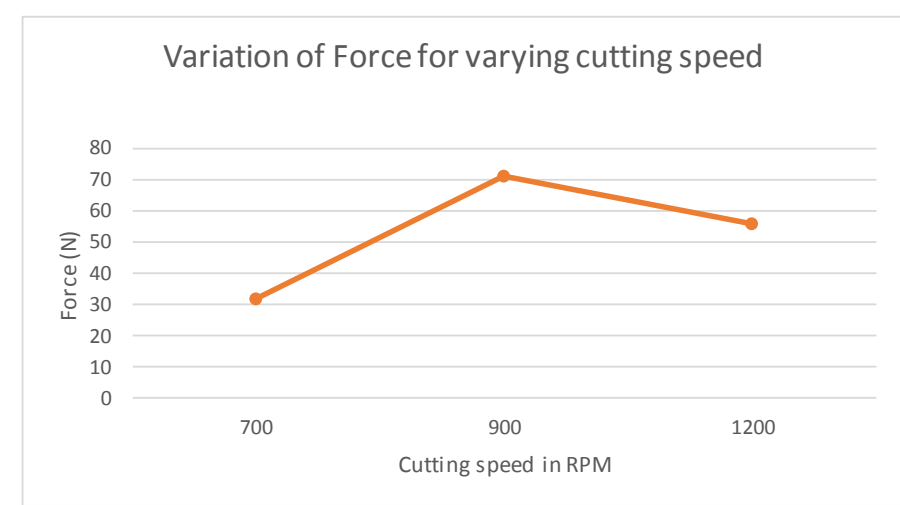

Fig. 5 Variation of force for different cutting speed (feed rate, $120 \mathrm{~mm} /$ minute; depth of cut, $0.3 \mathrm{~mm}$ ).

In addition to the above results, machining induced residual stresses was also studied. It was observed that the majority was compressive residual stresses within the component however tensile residual stresses were also present. The variation of residual stresses both compressive and tensile for varying speed at constant feed and depth of cut is shown in Fig. 8. The variation of the residual stresses both tensile and compressive for varying feed rate, at constant cutting speed and depth of cut is shown in Fig. 9.

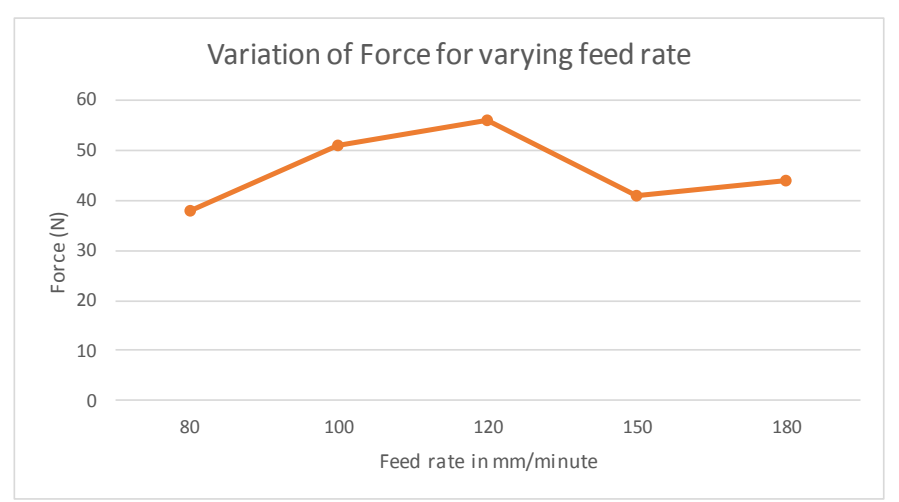

Fig. 6 Variation of force at varying feed rate (Cutting speed, 1200rpm; depth of cut, $0.3 \mathrm{~mm}$ ).

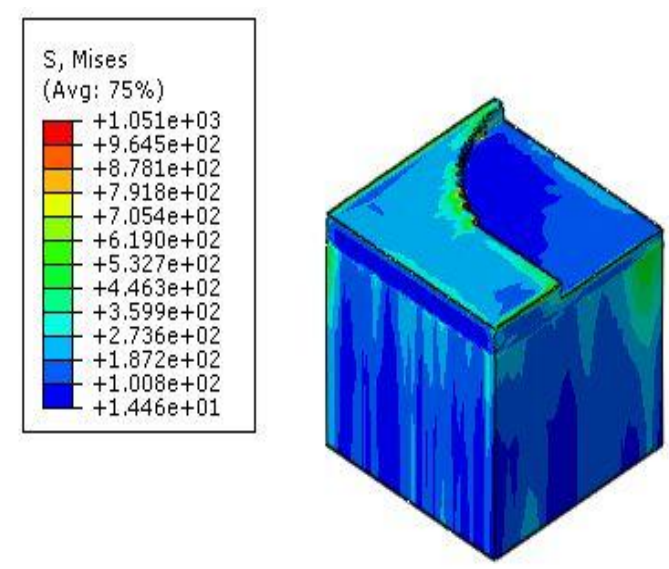


Fig. 7 Milled specimen showing von-Mises stress distribution (Cutting speed, $1200 \mathrm{rpm}$ : feed rate, $120 \mathrm{~mm} / \mathrm{minute}$; depth of cut, $0.3 \mathrm{~mm}$ ).

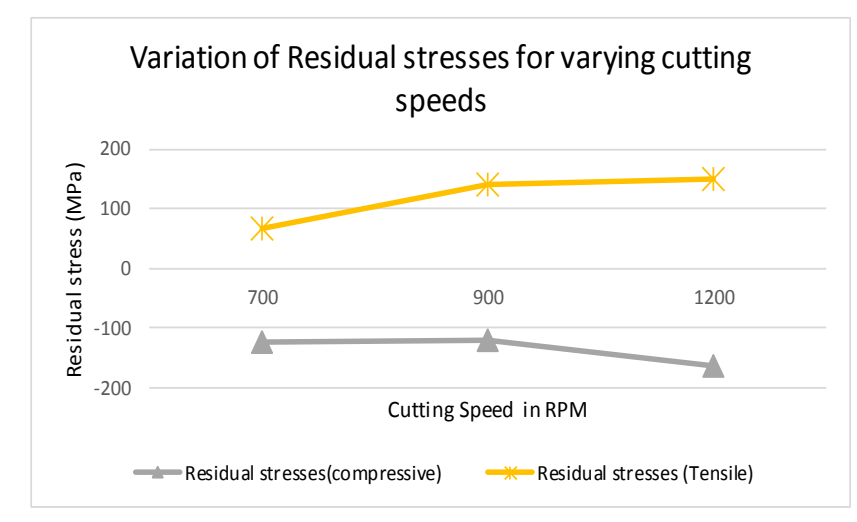

Fig. 8 Variation of Residual stresses for different cutting speed (feed rate, $120 \mathrm{~mm} / \mathrm{minute}$; depth of cut, $0.3 \mathrm{~mm}$ ).

From the force variation, it is observed that initially the force increase as the feed rate increases and later it stabilizes. The same trend of force variation was also observed when the cutting speed increases. As far as the residual stresses are concerned, tensile as well as compressive residual stresses are distributed in the machined specimen. However, compressive residual stresses are pre dominant on the cut surface. The advantage of using the numerical simulation is that the variation of the residual stresses along the depth as well as the plane can be studied. The tensile stresses showed increasing trend whereas the compressive stresses showed decreasing trend for varying feed rates. In the case of varying cutting speed both showed a decreasing trend for increasing cutting speeds.

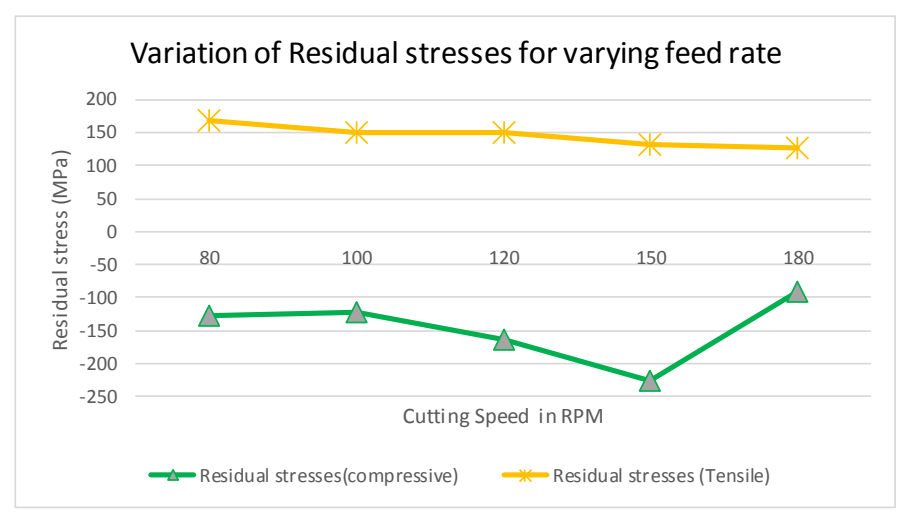

Fig. 9 Variation of Residual stresses at varying feed rate (Cutting speed, 1200rpm; depth of cut, $0.3 \mathrm{~mm}$ )

\section{Experimental Verification}

For validation of the model that is described in this work, a model used to predict the residual stresses for varying cutting conditions on AISI steel is used. The experimental design was done using Taguchi method, a well known Design of Experiments method [18]. The machining induced residual stresses for nine different cutting conditions was measured using X-ray diffraction method and compared with the numerical simulation results. The experimental and the numerical results are presented in Table 4 . The model was able to predict with an error of less than $15 \%$ in majority of the cases. 
Table 4 Experimental versus simulation results for AISI 1045 steel.

\begin{tabular}{cccccc}
\hline $\begin{array}{c}\text { Expt } \\
\text { No. }\end{array}$ & $\begin{array}{c}\text { Speed } \\
\text { in } \\
\mathrm{rpm}\end{array}$ & $\begin{array}{c}\text { Feed in } \\
\mathrm{mm} / \mathrm{min}\end{array}$ & $\begin{array}{c}\text { Depth of } \\
\text { cut in } \\
\mathrm{mm}\end{array}$ & $\begin{array}{c}\text { Stress } \\
\text { Values in } \\
\mathrm{MPa}\end{array}$ & $\begin{array}{c}\text { Simulation } \\
\text { results }\end{array}$ \\
\hline 1 & 355 & 20 & 0.2 & $-389.9 \pm 7.5$ & -354.8 \\
2 & 355 & 40 & 0.3 & $-448.3 \pm 8.0$ & -439.22 \\
3 & 355 & 80 & 0.5 & $-291.5 \pm 7.1$ & -218.9 \\
4 & 500 & 20 & 0.3 & $-523.1 \pm 5.3$ & -459.55 \\
5 & 500 & 40 & 0.5 & $-448.7 \pm 8.0$ & -456.81 \\
6 & 500 & 80 & 0.2 & $-245.0 \pm 10.6$ & -321.29 \\
7 & 710 & 20 & 0.5 & $-501.2 \pm 6.3$ & -405.88 \\
8 & 710 & 40 & 0.2 & $-253.4 \pm 10.9$ & -250.38 \\
9 & 710 & 80 & 0.3 & $-301.8 \pm 10.1$ & -279.75 \\
\hline
\end{tabular}

\section{Conclusion}

A mechanical numerical model was developed and the end-milling processes was studied. Force variation and machining induced residual stresses variation was determined using the Finite element model. The developed model is as improvisation of the existing research in the sense that oblique cutting is being modelled. Chip formation was observed and the machining induced residual stresses is mostly compressive on the newly obtained surface and there after it becomes tensile. Increase in cutting speed as well as increase in the feed rate increased the compressive residual stresses. Whereas the tensile residual stresses showed decreasing trend as the feed rate increased and showed an increasing trend as the cutting speed increased. Some of the limitations of the model include high computation time and it is not a thermos mechanical model.

The future work includes developing a Thermo-mechanical model and building a model to study the effect of sequential cuts on the machining induced residual stresses. Study of effect of sequential cuts is an important aspect [19] because the product is realised after multiple cuts irrespective of the machining process being used. Each cut is a plastic deformation process and it will have an effect of the induced residual stresses as it alters the physical as well as the metallurgical behaviour of the material.

\section{Supplementary data}

\subsection{Input file}

*Part, name=Part-3

*Nset, nset=Set-63, generate

$$
1,35568, \quad 1
$$

*Elset, elset=Set-63, generate

$$
1,31875, \quad 1
$$

** Section: Section-1

*Solid Section, elset=Set-63, controls=EC-1, material=steel

*End Part

**

*Part, name $=$ tool $6 \mathrm{~mm}$

*Node

*Surface, type=ELEMENT, name=m_Surf-2

_m_Surf-2_S2, S2

_m_Surf-2_S3, S3

_m_Surf-2_S4, S4

_m_Surf-2_S1, S1

*Surface, type=NODE, name=s_Set-9_CNS_, internal 
s_Set-9, 1 .

** Constraint: Tool_Body

*Rigid Body, ref node=_PickedSet16, elset=b_Set-1

*End Assembly

$* *$

** ELEMENT CONTROLS

$* *$

*Section Controls, name=EC-1, DISTORTION CONTROL=YES, length ratio=0.99, ELEMENT DELETION=YES, MAX DEGRADATION=0.9999, hourglass=RELAX STIFFNESS

1., $1 ., 1$.

$* *$

** MATERIALS

**

*Material, name=steel

*Damage Initiation, criterion=JOHNSON COOK

$-0.09,0.25,-0.5,0.014,3.87,1700 ., 850 ., 0.1$

*Damage Evolution, type=ENERGY

10.

*Density

4.4e-09,

*Elastic

110000., 0.33

*Inelastic Heat Fraction 0.9 ,

*Plastic, hardening $=\mathrm{JOHNSON}$ COOK

860., 683., 0.47, 1.,1700., 850.

*Rate Dependent, type $=\mathrm{JOHNSON}$ COOK

$0.034,0.1$

*Specific Heat

$6 \mathrm{e}+08$,

**

** INTERACTION PROPERTIES

$* *$

*Surface Interaction, name=Cont_Prop

*Friction

0.4 ,

*Surface Behavior, pressure-overclosure=HARD

$* *$

$* *$

** STEP: Step-1

**

*Step, name=Step-1, nlgeom=YES

*Dynamic, Explicit

, 5 .

*Bulk Viscosity

$0.06,1.2$

** Mass Scaling: Semi-Automatic

** Whole Model

*Fixed Mass Scaling, factor $=5000$.

**

** BOUNDARY CONDITIONS

**

** Name: Fixed_Wp Type: Symmetry/Antisymmetry/Encastre

*Boundary

Set-8, ENCASTRE 
** Name: Tool_Prop Type: Velocity/Angular velocity

*Boundary, type=VELOCITY

Set-4, 1, 1, -1.66

Set- $4,2,2$

Set- $4,3,3$

Set- $4,4,4$

Set-4, 5, 5, 125.66

Set- $4,6,6$

$* *$

** INTERACTIONS

$* *$

** Interaction: Int-1

*Contact Pair, interaction=Cont_Prop, mechanical constraint=PENALTY, cpset=Int-1

m_Surf-2, s_Set-9_CNS_

$* *$

** OUTPUT REQUESTS

**

*Restart, write, number interval=1, time marks=NO

$* *$

** FIELD OUTPUT: F-Output-1

$* *$

*Output, field, number interval $=500$

*Node Output

$\mathrm{A}, \mathrm{RF}, \mathrm{U}, \mathrm{V}$

*Element Output, directions=YES

EVF, LE, PE, PEEQ, PEEQVAVG, PEVAVG, S, STATUS, SVAVG

*Contact Output

CSTRESS,

$* *$

** HISTORY OUTPUT: H-Output-1

**

*Output, history

*Contact Output, cpset=Int-1

CFTM,

*End Step

\section{References}

[1] D. Umbrello, "Finite element simulation of conventional and high speed machining of Ti6Al4V alloy," J. Mater. Process. Technol., vol. 196, no. 1-3, pp. 79-87, 2008.

[2] Y. Gao, G. Wang, and B. Liu, "Chip formation characteristics in the machining of titanium alloys: a review," Int. J. Mach. Mach. Mater., vol. 18, no. 1/2, p. 155, 2016.

[3] T. H. C. Childs, P. J. Arrazola, P. Aristimuno, A. Garay, and I. Sacristan, "Ti6Al4V metal cutting chip formation experiments and modelling over a wide range of cutting speeds," J. Mater. Process. Technol., vol. 255, no. November 2017, pp. 898-913, 2018.

[4] D. Yameogo, B. Haddag, H. Makich, and M. Nouari, "Prediction of the Cutting Forces and Chip Morphology When Machining the Ti6Al4V Alloy Using a Microstructural Coupled Model," Procedia CIRP, vol. 58, pp. 335340, 2017.

[5] P. Niesłony, W. Grzesik, P. Laskowski, and J. Sienawski, "Numerical and experimental analysis of residual stresses generated in the machining of Ti6A14V titanium alloy," Procedia CIRP, vol. 13, pp. 78-83, 2014.

[6] Z. Pu, D. Umbrello, O. W. Dillon, and I. S. Jawahir, "Finite Element Simulation of Residual Stresses in Cryogenic Machining of AZ31B Mg Alloy,” Procedia CIRP, vol. 13, pp. 282-287, 2014.

[7] T. Özel and E. Zeren, "Finite element modeling the influence of edge roundness on the stress and temperature fields induced by high-speed machining," Int. J. Adv. Manuf. Technol., vol. 35, no. 3-4, pp. 255-267, 2007.

[8] A. Muñoz-Sánchez, J. A. Canteli, J. L. Cantero, and M. H. Miguélez, "Numerical analysis of the tool wear effect 
in the machining induced residual stresses," Simul. Model. Pract. Theory, vol. 19, no. 2, pp. 872-886, 2011.

[9] M. Mohammadpour, M. R. Razfar, and R. Jalili Saffar, "Numerical investigating the effect of machining parameters on residual stresses in orthogonal cutting," Simul. Model. Pract. Theory, vol. 18, no. 3, pp. 378-389, 2010.

[10] Francis Ducobu, Edouard Riviere, Enrico Filippi, "Application of the Coupled Eulerian-Lagrangian (CEL) method to the modeling of orthogonal cutting," European Journal of Mechanics - A/Solid., vol. 59, pp. 58-66, 2016.

[11] Sedat Komurcu, Abdullah Gedikelli, "Numerical Modelling of the In-Plane Loaded Homogenized Masonary Walls," Period. Eng. Nat. Sci., vol. 5, no. 3, pp. 314-321, 2017.

[12] P. O. De Micheli and K. Mocellin, " $2 \mathrm{D}$ high speed machining simulations using a new explicit formulation with linear triangular elements," Int. J. Mach. Mach. Mater., vol. 9, no. 3/4, p. 266, 2011.

[13] F. Ducobu, E. Rivière-Lorphèvre, and E. Filippi, "On the introduction of adaptive mass scaling in a finite element model of Ti6A14V orthogonal cutting," Simul. Model. Pract. Theory, vol. 53, pp. 1-14, 2015.

[14] F. Ducobu, P. J. Arrazola, E. Rivière-Lorphèvre, G. O. De Zarate, A. Madariaga, and E. Filippi, "The CEL Method as an Alternative to the Current Modelling Approaches for Ti6A14V Orthogonal Cutting Simulation," Procedia CIRP, vol. 58, pp. 245-250, 2017.

[15] Y. Karpat, "Temperature dependent flow softening of titanium alloy Ti6Al4V: An investigation using finite element simulation of machining," J. Mater. Process. Technol., vol. 211, no. 4, pp. 737-749, 2011.

[16] S. Fredrick and M. Building, "Evaluation of drilling process in Ti6Al4V using 3D FE simulation Ozden Isbilir and Elaheh Ghassemieh *," Int. J. Mach. Mach. Mater., vol. 13, no. 2-3, pp. 174-190, 2013.

[17] K. Prakash Marimuthu, H. P. Thirtha Prasada, and C. S. Chethan Kumar, "3D finite element model to predict machining induced residual stresses using arbitrary lagrangian eulerian approach,” J. Eng. Sci. Technol., vol. 13, no. 2,2018 .

[18] B. Durakovic, "Design of experiments application, concepts, examples: State of the art," Period. Eng. Nat. Sci., vol. 5, no. 3, pp. 421-439, 2017.

[19] P. Krishnakumar, A. V Vidyapeetham, K. P. Marimuthu, K. Rameshkumar, and K. I. Ramachandran, "Finite element simulation of effect of residual stresses during orthogonal machining using ALE approach," Int. J. Mach. Mach. Mater., vol. 14, no. 3, pp. 213-229, 2013. 